\title{
The Greek Rhotic in /rC/ Sequences: An Acoustic and Electropalatographic Study
}

\author{
Katerina Nicolaidis and Mary Baltazani \\ Aristotle University of Thessaloniki, University of loannina \\ knicol@enl.auth.gr,mbaltaz@cc.uoi.gr
}

\begin{abstract}
This paper analyses acoustic and electropalatographic data to examine rhotic production in $/ \mathrm{rC} /$ sequences in Greek. The rhotic was typically produced with a single constriction phase and a vocoid following the constriction and preceding the consonant. The duration data showed that the vocoid was longer than the constriction with formants similar to the nuclear vowel but more centralised. The articulatory analysis showed an alveolar rhotic with variation in place and degree of constriction (ranging from fully constricted to more open articulations) due to context and speaker. The data indicate tap production superimposed on a vocalic gesture which is necessary for the ballistic movement to occur.
\end{abstract}

\section{Introduction}

Rhotic production has been reported to vary within and across languages. Previous literature has documented variation in manner and place of articulation due to factors such as context, position, speech rate and dialect (Lindau 1985; Inouye 1995; Ladefoged \& Maddieson 1996; Recasens \& Pallarès 1999; Recasens \& Espinosa 2007). Variability in rhotic production has also been reported for Greek. Descriptions of the Greek consonantal system mainly based on impressionistic

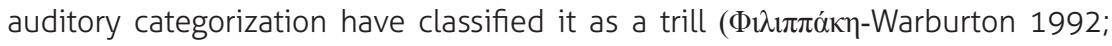
Nespor 1996) or as a tap (e.g. Arvaniti 1999). Experimental studies have verified tap production but have also shown approximant articulation (Nicolaidis 2001; Baltazani 2005, 2009). Variation in the place of articulation of the rhotic has also been reported ranging between alveolar, retracted alveolar and postalveolar productions (Nicolaidis 2001; Nicolaidis and Baltazani 2011; Baltazani and Nicolaidis (2012)). Further context-based variation has also been reported. In particular, tap productions have been described to occur in initial and intervocalic position (Arvaniti 1999; Nicolaidis 2001; Baltazani 2005, 2009) while in clusters with stops or fricatives there is evidence of the production of a vocoid between

(cc) BY-NC-ND 
the consonant and the rhotic (Baltazani 2009; Nicolaidis and Baltazani 2011). The nature of the latter articulation, which involves the presence of a vocoid, has been debated in the literature. On the one hand, it has been claimed to indicate trill production (Arvaniti 2007). On the other, it has been interpreted to manifest the production of a tap which involves a vowel-like transition between the consonant and the rhotic (Baltazani 2009). Evidence of such realization of the rhotic in clusters, i.e. as a combination of a tap and a vowel-like interval, has also been reported for other languages including Spanish, Catalan, French, Finnish, Hungarian, Hamburg German and Romanian (Navarro Tomás 1918; Rochette 1973; Harms 1976; Jannedy 1994; Bradley \& Schmeiser, 2003; Bradley 2004; Colantoni \& Steele, 2005; Recasens \& Espinosa, 2007; Vago \& Gósy 2007; Savu 2012).

The current study aims to investigate variation in the production of the Greek rhotic in /r-stop/ and /r-fricative/ sequences. It is part of a larger project which analyses simultaneous acoustic and articulatory data on the Greek rhotic in order to examine variation due to position and context. This paper examines duration and formant frequency data aiming to investigate the realization of both the constriction phase and the vocoid in these $/ \mathrm{rC} /$ sequences. Formant frequency data are also examined for the vowels preceding and following the sequences in order to explore their influence on the vocoid realization. The paper also analyses articulatory data in order to examine variability in rhotic production as a function of context and speaker. Overall, the study aims to examine (a) whether the vocoid is systematically present during rhotic production in $/ \mathrm{rC} /$ sequences, (b) whether the vocoid is a neutral vowel or affected by context, (c) the range of duration of the vocoid compared to the constriction phase, (d) the influence of the place and manner of articulation of the following consonant on the articulation of the rhotic, (e) the influence of the vocalic environment on the acoustic and articulatory characteristics of the rhotic (see also (b)), and (e) evidence suggesting a tap vs. trill production in $/ \mathrm{rC} /$ sequences.

\section{Methodology}

\subsection{Speech Material and Subjects}

Words containing a $/ \mathrm{VrCV} /$ sequence were recorded with $C=/ p, t, k, f, \theta, x /$ and $V=/ i, e, a, 0, u /{ }^{1}$. The test words were embedded in the carrier phrase

$\mathbf{1}$ In this paper, the /r/ symbol is used for the Greek rhotic for practical reasons. Similarly, the vowels are transcribed as /i, e, a, o, u/. For a description of the quality of the Greek vowels, see Arvaniti (1999, 2007). 
[i 'leksi___ ine a ' pli] 'The word_ is simple'. Only symmetrical sequences were recorded, i.e. with the same vowel before and after the $/ \mathrm{rC} /$ sequence. All words were up to four syllables long. The location of the stress varied so that the majority of items in the speech material were real words (see appendix). Five Greek adult speakers (three female and two male) repeated the speech material five times at a comfortable speaking rate in a sound-treated room in the Phonetics Laboratory of the School of English at Aristotle University. In total, 750 words ( 6 Cs $\times 5$ Vs $\times 5$ repetitions $\times 5$ speakers) were recorded.

\subsection{Data Recording and Analysis}

The British EPG system marketed by Articulate Instruments was used to record acoustic and electropalatographic (EPG) data simultaneously. In addition, acoustic data were independently recorded using a Marantz PMD 660 digital recorder with a Røde NT1-A cardiod condenser microphone and were subsequently analysed using PRAAT. For segmentation and annotation of the rhotic, the different phases of its production were identified on the acoustic data. The rhotic typically consisted of two phases, i.e. a constriction phase and a vocoid following the constriction and preceding the obstruent in the / $\mathrm{VrCV} /$ sequences. The constriction phase boundaries were identified at the offset of the formant structure of the preceding vowel and at the onset of following vocoid formants. The vocoid boundaries were identified at the onset and offset of voiced formant structure (Figure 1), or else, in cases of the presence of frication noise or a whispered vocoid, at the onset/offset of voiceless formant
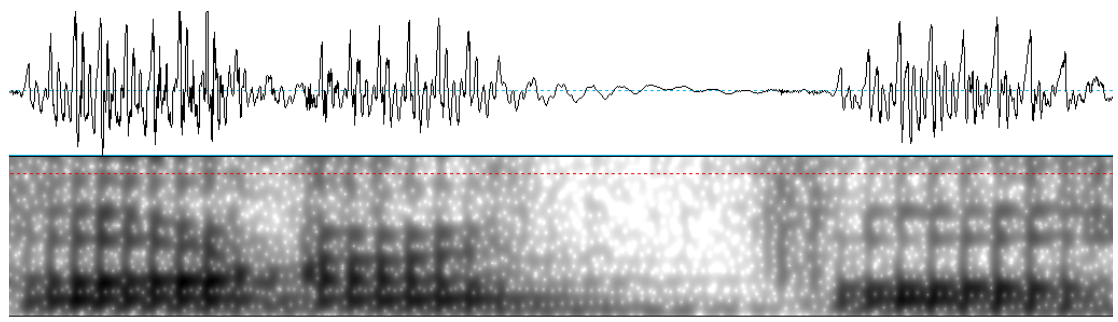

skorpoxori

\begin{tabular}{|l|l|l|l|l|}
\hline a1 & r1 & r2 & c & a2 \\
\hline
\end{tabular}

Figure 1. Example of segmentation of the /rC/ sequence in the word [skorpo'xori] (the labels 'a1', 'a2' correspond to the preceding and following vowels respectively, ' $r 1$ ' to the constriction phase of the rhotic, ' $r 2$ ' to the vocoid phase of the rhotic, ' $c$ ' to the obstruent following the rhotic). 
structure (Figure 2). Measurements of F1, F2, F3 formants of both the vocoid and the flanking vowels in the $/ \mathrm{VrCV} /$ sequence were taken at the $1 / 4,1 / 2$, and $3 / 4$ points. In this paper, we report results only for F1 and F2 at the midpoint of the vocoid and the preceding tautosyllabic vowel.

Electropalatography records lingual contact with the palate in continuous speech. A thin custom-made artificial palate embedded with electrodes on its surface is worn by the subjects to register linguo-palatal contact. For the British system used in this study, the artificial palate has 62 electrodes on its surface which are distributed in eight rows (Figure 3). The front four rows correspond to the alveolar zone and the back four rows to the palatal zone. The alveolar zone is subdivided to the alveolar and postalveolar regions (rows 1 to 2 and 3 to 4 respectively). The first two columns on the left and right side of the palate are characterized as lateral and the four remaining columns as central (Gibbon \& Nicolaidis 1999; Recasens et al 1993).

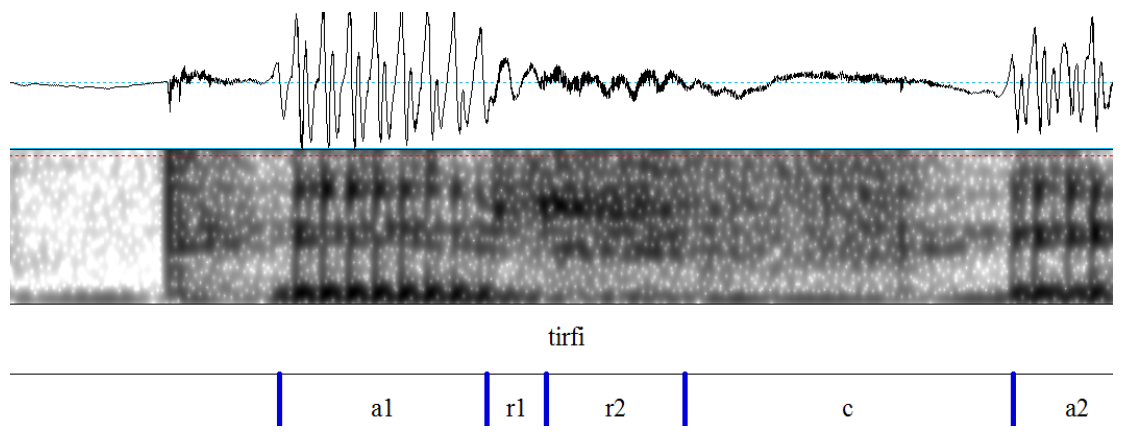

Figure 2. Example of segmentation of the /rC/ sequence in the word ['tirfi] (for the labels used, see caption of figure 1).

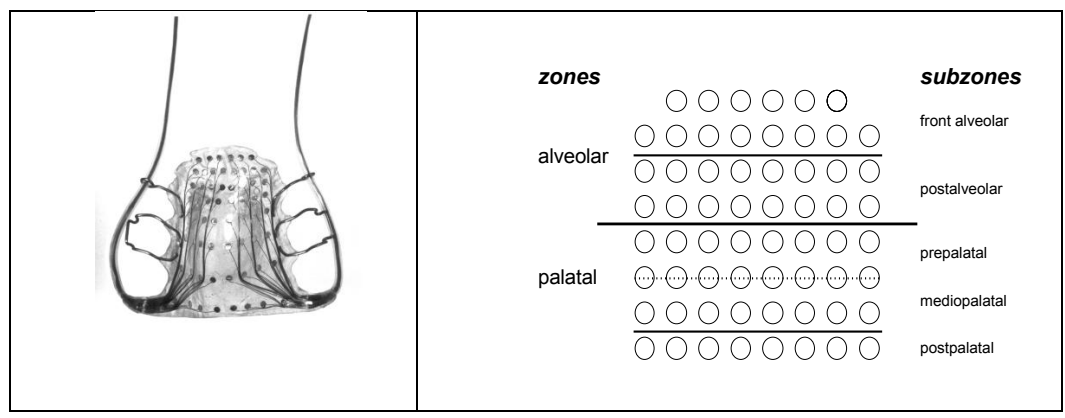

Figure 3. The artificial palate used in electropalatography for the British system marketed by Articulate instruments (left). Schematic representation of electrodes and division of electrodes into zones and subzones (right). 
For the articulatory analysis, Articulate Assistant (version 1.18) was used for data display, segmentation and analysis. The place of articulation of the rhotic always occurred in the alveolar zone. Thus, the first EPG frame of maximum contact/constriction in the four front rows was identified for each rhotic (Figure 4). For the majority of tokens, the frame of maximum contact coincided with the frame of maximum constriction. When it did not, the frame of maximum constriction in the alveolar zone was annotated. The percentage frequency of electrode activation of the entire palate at the frame of maximum contact/ constriction over five repetitions was then calculated for each word (see, e.g., Figure 12).

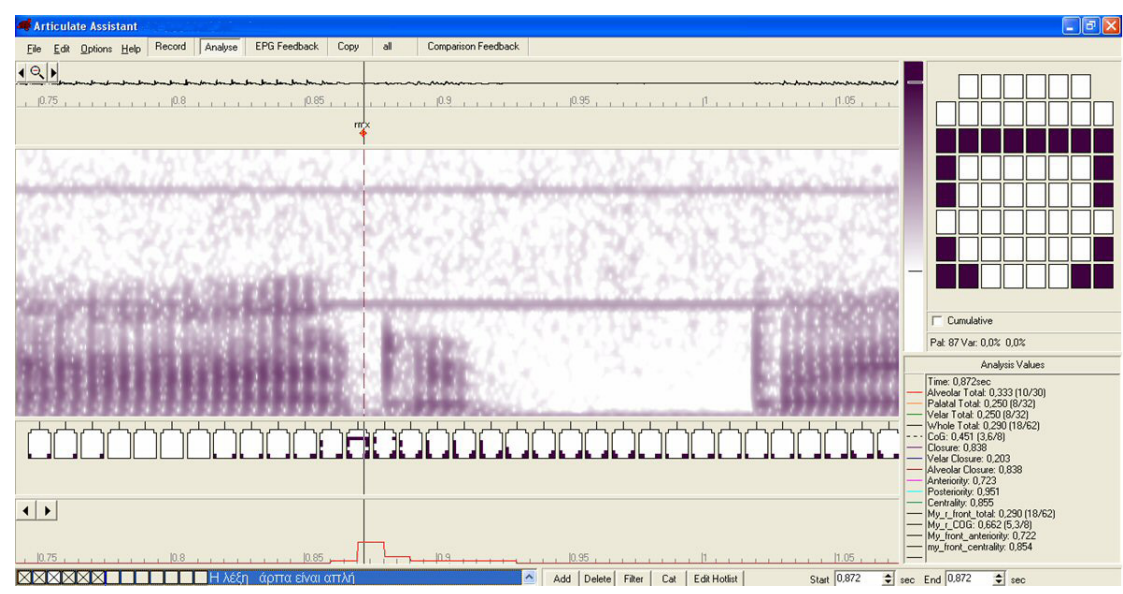

Figure 4. Screen display from Articulate Assistant showing acoustic waveform, spectrogram, EPG palatograms and contact totals display (alveolar total) for the rhotic in the word ['arpa] produced by speaker MM. The annotation line corresponds to the first frame of maximum contact/constriction in the alveolar zone. The corresponding palatogram is shown at the top right of the display.

\section{Results}

\subsection{Acoustic Analysis}

The acoustic analysis showed that the rhotic in $/ \mathrm{rC} /$ sequences is typically a tap which consists of two phases: a single constriction phase and a short vocoid appearing between the rhotic constriction and the obstruent (see section 3.2 for details). A tap realization of the rhotic was also reported for $/ \mathrm{Cr} /$ clusters in Nicolaidis \& Baltazani (2011), where only 5 tokens out of a total of 750 tokens were produced with a second very open approximation phase suggesting 
possible trill production. A tap realisation was also reported in Baltazani \& Nicolaidis (2012) with the exception of 10 trills out of the 375 tokens analysed. These results clearly demonstrate that the Greek rhotic is not a trill but involves a single tap-like gesture superimposed on a vocalic one.

Moreover, the acoustic measurements revealed variability in the structure of both rhotic components in $/ \mathrm{rC} /$ sequences (Figures 5-7). Specifically, the constriction phase varied between tokens with presence of silence and a burst, suggesting complete articulatory closure (Figure 5), and tokens with frication noise (Figure 6), suggesting incomplete closure, something which is corroborated by the articulatory analysis (section 3.2). Further variability was observed in the vocoid production which ranged from a modal vowel structure (Figures 5 and 6) to a whispered one (Figure 7). Finally, observation of the rhotic data in $/ \mathrm{rC}$ / sequences examined in this paper vs. $/ \mathrm{Cr} /$ clusters examined in previous work (Nicolaidis \& Baltazani 2011) indicates that there was a tendency for more tokens with whispered vocoids or frication noise during the constriction phase in heterosyllabic / rC/ sequences than in homosyllabic / $\mathrm{Cr} /$ clusters. This suggests more assimilatory effects of the following voiceless obstruent in /rC/ sequences.

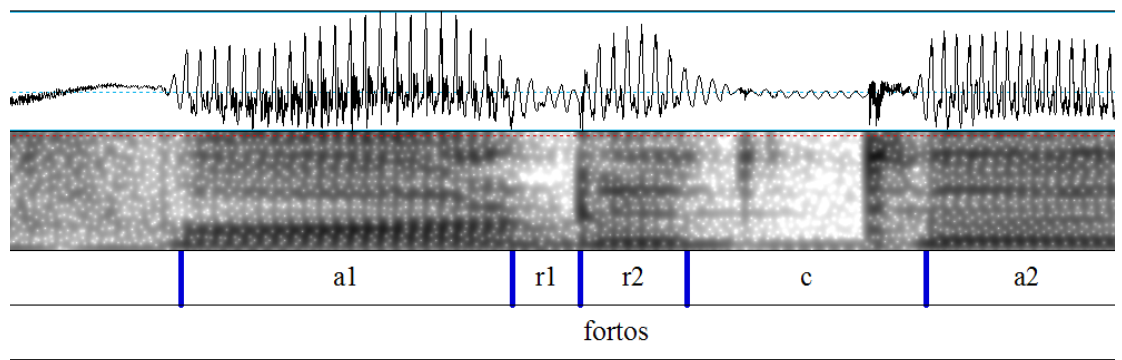

Figure 5. A token of $/ \mathrm{r} /$ in the word ['fortos] produced by speaker MM with acoustic evidence suggesting complete closure during the constriction phase and modal vowel quality for the vocoid (for the labels used, see caption of Figure 1).
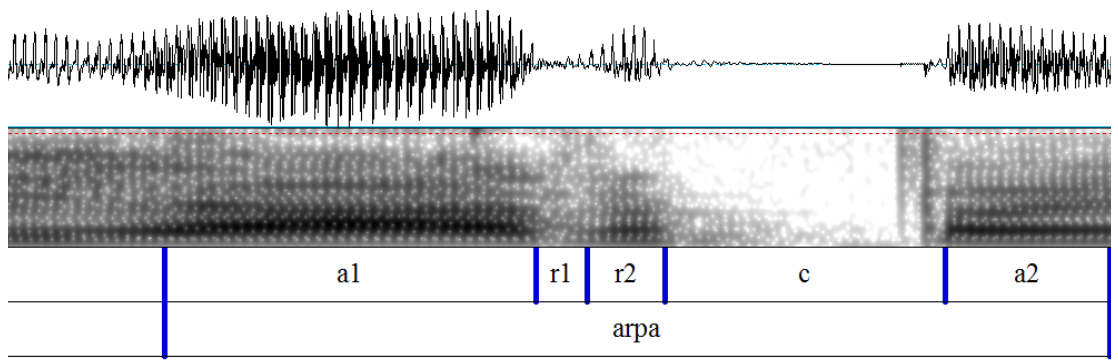

Figure 6. A token of $/ r /$ in the word ['arpa] produced by speaker TP with frication noise during the constriction phase (for the labels used, see caption of Figure 1). 


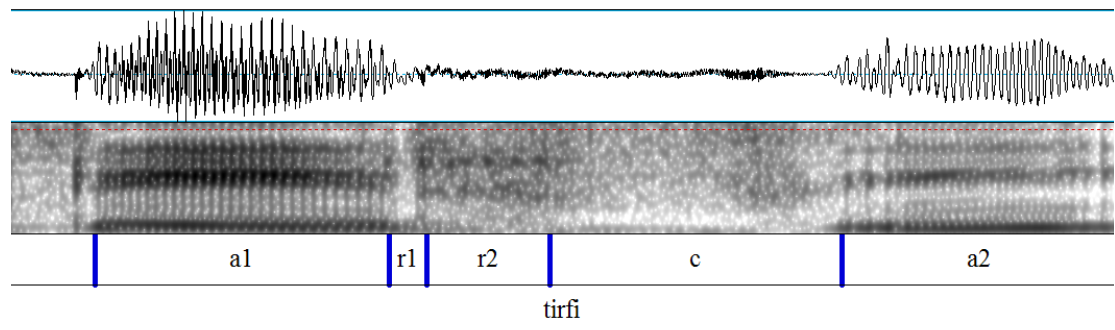

Figure 7. A token of $/ r /$ in the word ['tirfi] produced by speaker MM with acoustic evidence suggesting complete closure during the constriction phase and a whispered vowel quality during the vocoid (for the labels used, see caption of Figure 1).

As far as the duration of the rhotic components is concerned, in $/ \mathrm{rC} /$ sequences the vocoid was found to be longer than the constriction phase across experimental conditions. Table 1 presents average durations for the constriction and vocoid for all vocalic contexts across speakers and repetitions. The vocoid in all vocalic contexts is on average $7 \mathrm{~ms}$ longer than the constriction. Longer duration for the vocoid compared to the constriction phase was also reported in Nicolaidis \& Baltazani (2011) for / Cr/ clusters as well as in Baltazani \& Nicolaidis (2012) for / $r /$ in phrase initial position.

Table 1.

Average durations for the constriction and vocoid phases of the rhotic in all vocalic contexts.

\begin{tabular}{|c|c|c|}
\hline V context & Constriction duration (ms) & Vocoid duration (ms) \\
\hline $\mathrm{i}$ & 28 & 37 \\
\hline $\mathrm{e}$ & 25 & 31 \\
\hline $\mathrm{a}$ & 26 & 31 \\
\hline $\mathrm{o}$ & 22 & 30 \\
\hline $\mathrm{u}$ & 23 & 32 \\
\hline Average & 25 & 32 \\
\hline
\end{tabular}

Variability both in the duration of the rhotic components and the duration differences between the two components is shown in Figure 8, where results from each of the five speakers are shown (from top left to bottom right, speakers TP, RP, $K N, A T$, and MM). Speaker AT (bottom left) produced the shortest segments and the smallest differences between the constriction (shown in black) and vocoid duration (grey), speaker TP (top left) produced the longest segments, while for speaker MM (bottom right) there was the biggest durational difference between the constriction and the vocoid. 

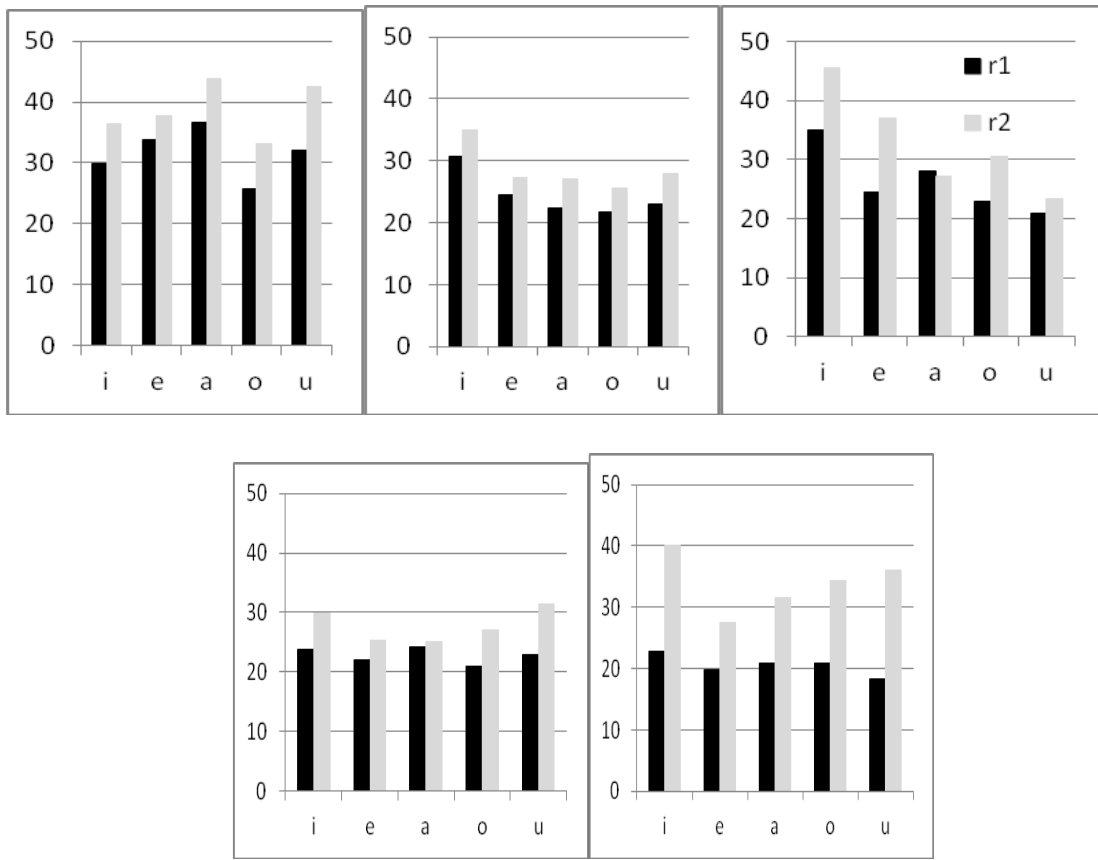

Figure 8. Speaker variability in the duration of the constriction phase ( $r 1=b l a c k)$ and the vocoid ( $r 2$ =grey). Results for speakers TP, RP, KN, AT, and MM are shown from top left to bottom right.

The F1, F2 formants of the vocoid and the nuclear vowel $\mathrm{V} 1$ in $/ \mathrm{rC}$ / sequences were compared to determine the effect of the latter on the former. The results showed that the vocoid formant values are similar to those of the nuclear vowel (V1), with a clear tendency to be more centralized than V1. However, there is variability in the amount of centralization among vocalic contexts and speakers, as Figure 9 shows. For example, in the context of nonhigh vowels, speakers TP (top left), RP (mid left) and MM (bottom) produced the vocoid with considerably higher $F 1$ values compared to $V 1$, whereas the other two speakers did not show such large differences. Variability was also evident in the context of high vowels, e.g. for MM (bottom) large differences in F2 between the vocoids and the nuclear vowels /i/ and /u/ are evident showing considerable centralization of the vocoids; relatively large differences in F2 are also evident between the vocoid and /u/ for KN (top right) and the vocoid and /i/ for AT (middle right). The other speakers do not show such large differences. As can be seen, therefore, the data show a centralization tendency with notable variability in the F1, F2 values of the vocoid across speakers and vocalic contexts. 


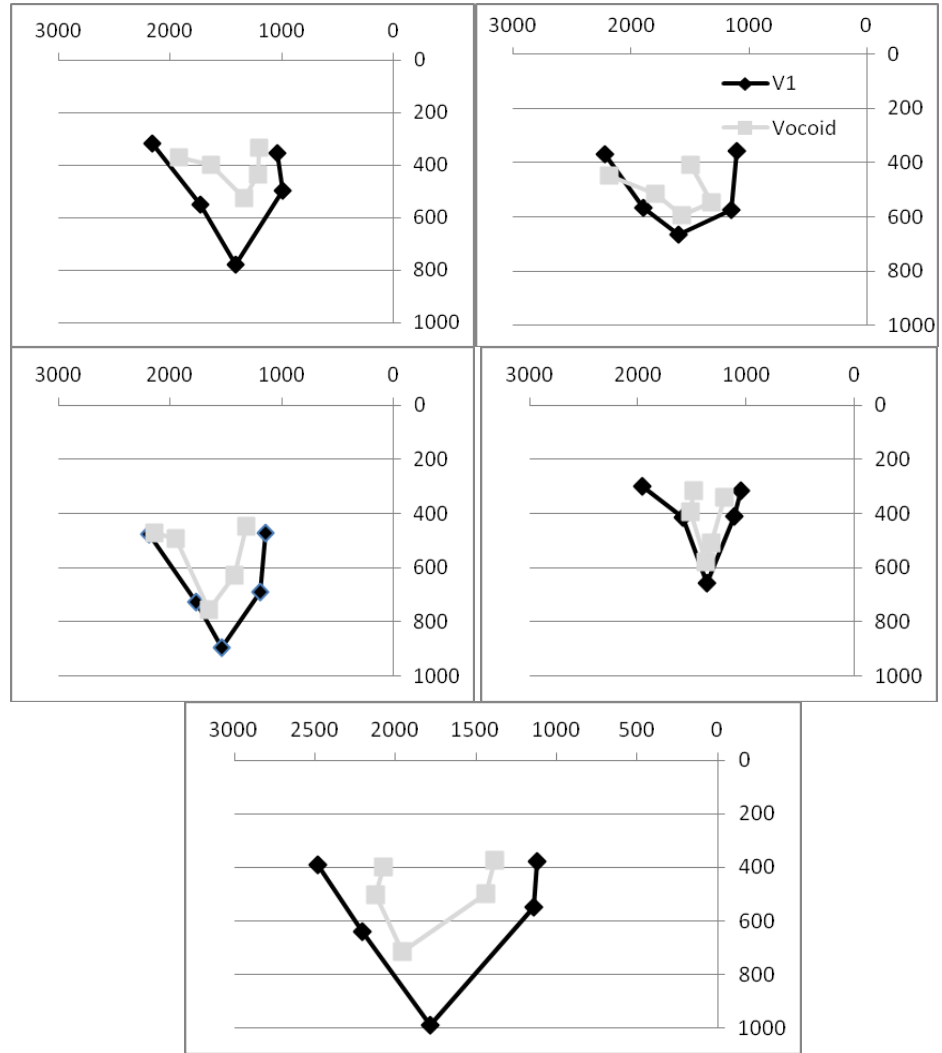

Figure 9. Comparison of V1 (black line) and vocoid (grey line) formant values for the five speakers, from top left to bottom, TP, KN, RP, AT, MM.

The amount of variability in the realization of both the vocoid and V1 can be appreciated in Figure 10, which presents the Euclidean distance between the vocoid and V1 across speakers and vocalic contexts. This distance is the square root of the sum of the squares of the difference between the vowel formant frequencies ${ }^{2}$ of each V1 (nuclear vowel) and corresponding V2 (vocoid). Bigger numbers indicate greater distance between the vocoid and $V_{1}$ formants, hence a greater amount of centralization for the vocoid. The most consistent trend is variation, since no generalized statement can be made across speakers or vocalic contexts ${ }^{3}$.

$\mathbf{2} \mathrm{ED}=\mathrm{V}\left((\mathrm{F} 1 \mathrm{~V} 1-\mathrm{F} 1 \mathrm{~V} 2)^{2}+(\mathrm{F} 2 \mathrm{~V} 1-\mathrm{F} 2 \mathrm{~V} 2)^{2}\right)$ where $\mathrm{V} 1=$ nuclear vowel and $\mathrm{V} 2=$ vocoid.

3 Note that TP shows less variability across vocalic contexts compared to the other speakers. 


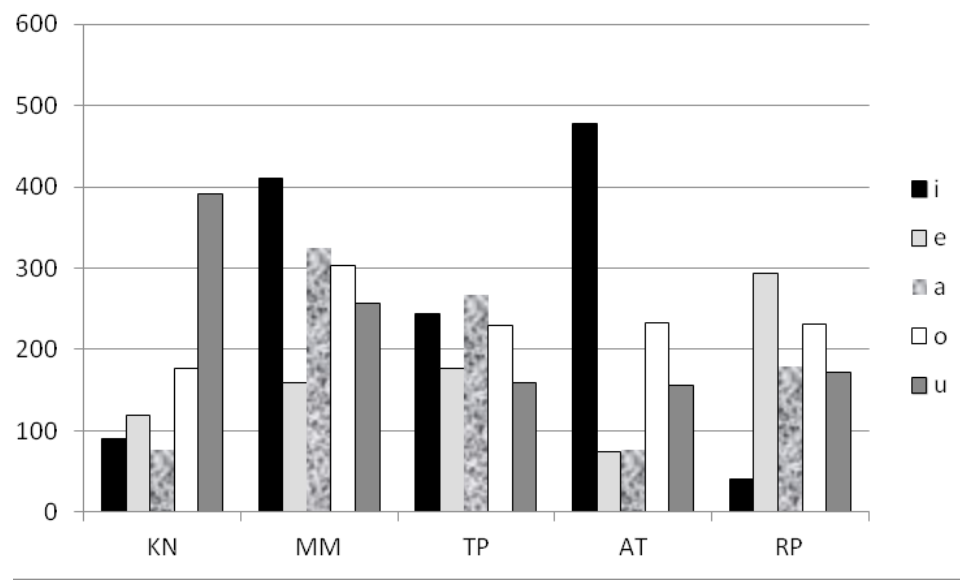

Figure 10. The Euclidean distance between the vocoid and V1 across speakers and vocalic contexts.

\subsection{Articulatory Analysis}

The electropalatographic data also showed that there was typically one constriction present during the production of the rhotic in $/ \mathrm{rC} /$ sequences which was followed by a vocoid before the obstruent (Figure 11 ). Thus, $/ \mathrm{rC} /$ sequences typically involve a tap-like gesture and not a trill. This gesture varied in terms of the degree of constriction involving instances of complete closure across a row of electrodes and tokens with incomplete closure. Different realizations of incomplete closure were evident which related to the degree of approximation of the lingual gesture to the palate. They ranged from cases with considerable approximation to others involving very open articulations. Such articulatory manifestations related to variation in the acoustic signal with evidence of a stop-like pattern in cases of complete constriction and of approximant formant transitions in cases of relatively open articulations. Presence of noise was also evident in several tokens involving incomplete constriction. Figure 11(a, b) presents two repetitions of the rhotic in the word /'tirpis/ produced by the same speaker with complete and incomplete constriction. Overall, $57 \%$ of the rhotics were realized with incomplete constriction (426 out of 749 tokens). Table 2 shows the number of tokens produced with incomplete constriction for the five speakers. Evidence of considerable speaker variability is observed with over $70 \%$ of tokens produced with incomplete constriction by speaker KN and just $25 \%$ by MM. In addition, more open productions were found in the environment of a following fricative compared to the stop context (250 vs. 176), (see also the analysis of contextual variation below). 


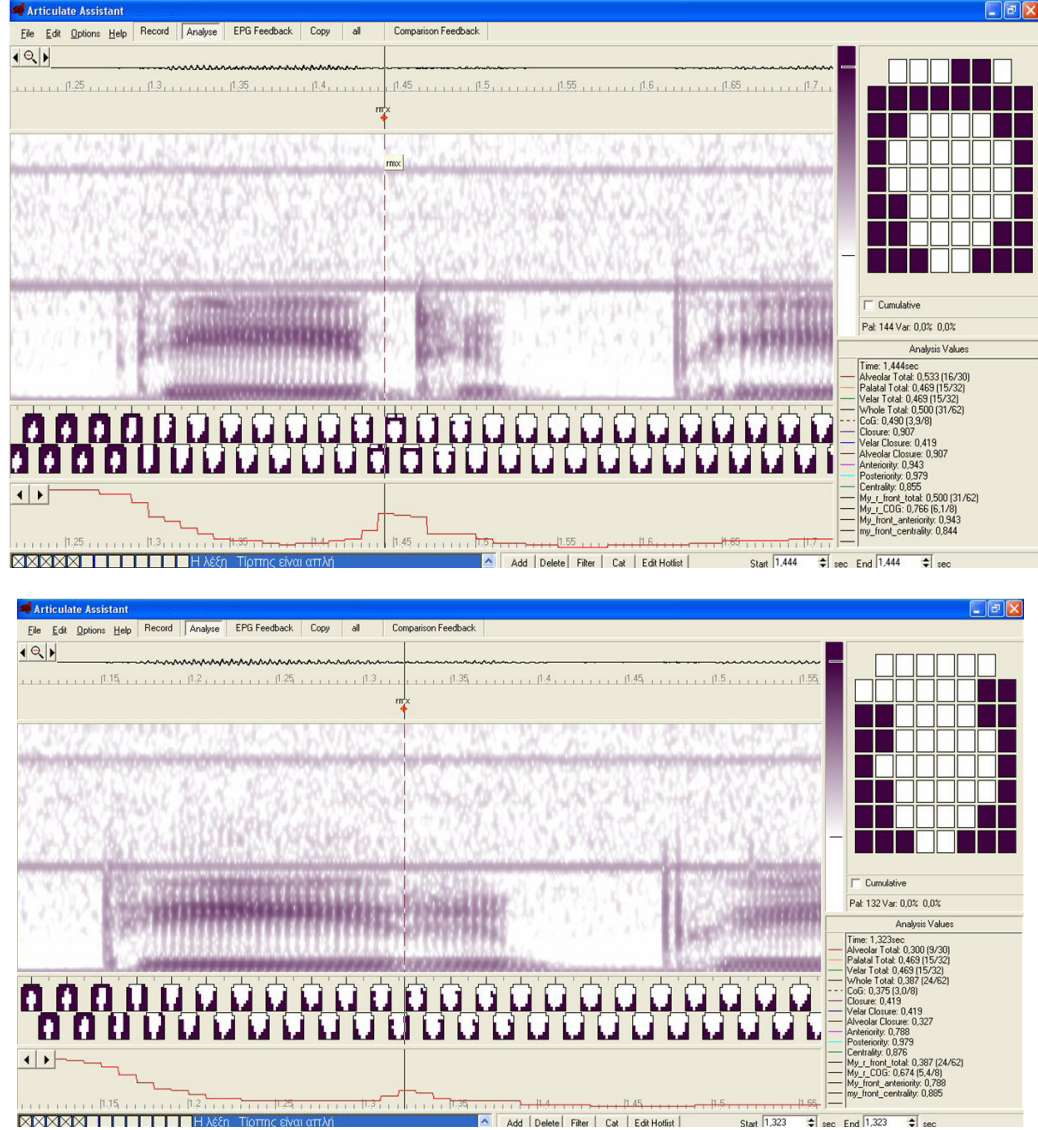

Figure $\mathbf{1 1}(\mathbf{a}, \mathbf{b})$. Acoustic and electropalatographic data for the rhotic in the word ['tirpis] produced by speaker MM. In (a) the rhotic is produced with complete constriction and a stop-like pattern on the acoustic data; in (b) there is incomplete constriction and presence of formant structure. The corresponding palatograms at the point of maximum contact/constriction are shown at the right top of the displays.

Table 2.

Number of tokens produced with incomplete constriction in /r-stop/ and /r-fricative/ sequences for the five speakers.

\begin{tabular}{|l|c|c|c|c|c|}
\hline & KN & AT & RP & MM & TP \\
\hline r-stop & 59 & 41 & 34 & 14 & 28 \\
\hline r-fric & 71 & 62 & 48 & 30 & 39 \\
\hline Total & 130 & 103 & 82 & 44 & 67 \\
\hline
\end{tabular}


Contextual influence on the place of articulation of the rhotic was also evident. More fronted productions were found in the environment of the front vowels /i, e/ and more retracted productions in the context of the back vowels. In some consonantal contexts, the rhotic was most retracted when next to /a/ and /o/. Figure 12 shows that constriction is more anterior in the environment of $/ \mathrm{i} /$, i.e. on the first and second row of electrodes; constriction gradually retracts in the other vowel contexts with contact on the 2nd-3rd rows in the context of /e/, third row in the context of /a/ and 3rd-4th rows in the context of $/ 0, \mathrm{u} /$. Thus, while the rhotic is always articulated in the alveolar zone, its place of articulation ranges between alveolar, retracted alveolar, advanced postalveolar or postalveolar depending on the vocalic context.

Some evidence of contextual influence on the place of articulation of the rhotic due to the following consonantal context was also found, although large variation was present among speakers and contexts. Figure 13 shows an example of more anterior production of the rhotic in the environment of / $t /$ compared to the bilabial context, which is more evident mainly in the context of /a, o, u/.

\begin{tabular}{|c|c|c|c|c|}
\hline /irpi/ & /erpe/ & /arpa/ & /orpo/ & /urpu/ \\
\hline 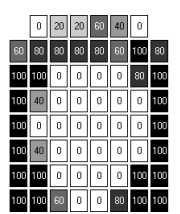 & 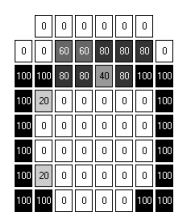 & 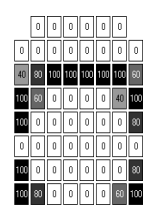 & 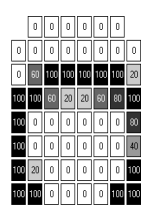 & 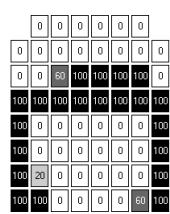 \\
\hline
\end{tabular}

Figure 12. EPG palatograms displaying percentage frequency of electrode activation over five repetitions during the production of the $/ \mathrm{r} / \mathrm{in} / \mathrm{rp} /$ sequences by speaker MM.
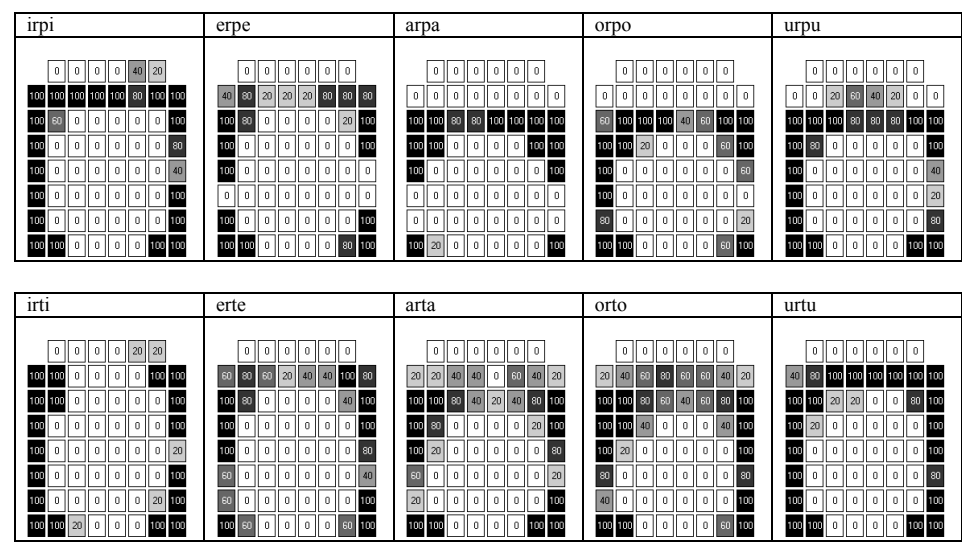

Figure 13. EPG palatograms displaying percentage frequency of electrode activation over five repetitions during the production of the $/ \mathrm{r} / \mathrm{in} / \mathrm{rp} /$ and $/ \mathrm{rt} /$ sequences by speaker AT. 
An effect of the consonantal context on the degree of rhotic constriction was found. More open productions were evident in the environment of a following fricative compared to the stop context (Table 2). A comparison of the palatograms for the /rp/ sequences in Figure 13 (top) with the /rf/ sequences in Figure 14 produced by speaker AT shows differences in the degree of constriction of the rhotic, i.e. more open articulation in the environment of the fricative /f/ compared to the stop /p/. This was true for the rhotic not only in the context of a lingual consonant, dental or velar, where the tongue is involved both in the articulation of the rhotic and the consonant, but also in the labial consonantal environment which involves an independent articulatory system.

Variation was also evident in the articulation of the rhotic as a function of the speaker. Variability was found both within and across speakers. Figure 15 shows differences in the degree of constriction and place of articulation of the $/ r /$ in $/ r k /$ sequences for speakers TP and KN. The former shows more constricted

\begin{tabular}{|c|c|c|c|c|}
\hline irfi & erfe & arfa & orfo & urfu \\
\hline 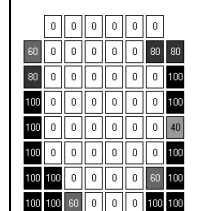 & 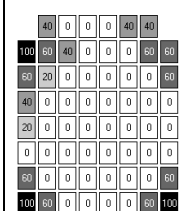 & 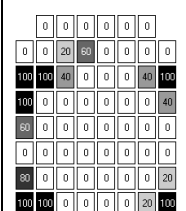 & 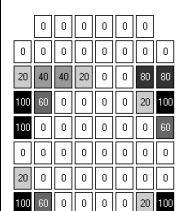 & 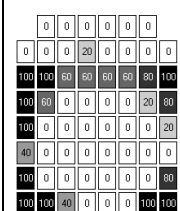 \\
\hline
\end{tabular}

Figure 14. EPG palatograms displaying percentage frequency of electrode activation over five repetitions during the production of the $/ \mathrm{r} / \mathrm{in} / \mathrm{rf} /$ sequences by speaker AT.

\begin{tabular}{|c|c|c|c|c|}
\hline /irki/ & /erke/ & /arka/ & /orko/ & /urku/ \\
\hline 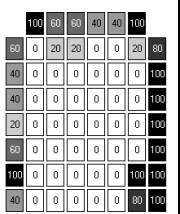 & 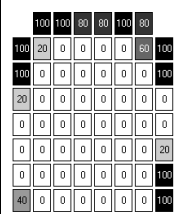 & 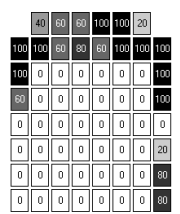 & 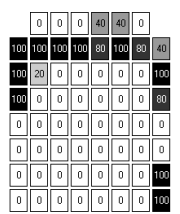 & 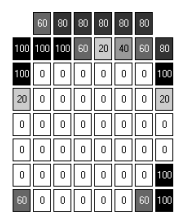 \\
\hline
\end{tabular}

\begin{tabular}{|c|c|c|c|c|}
\hline irki/ & /erke/ & /arka/ & /orko/ & /urku/ \\
\hline 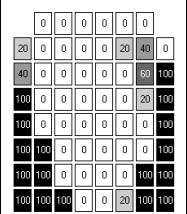 & 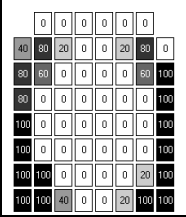 & 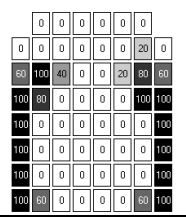 & 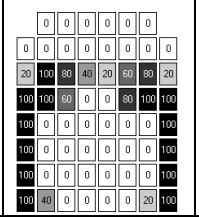 & 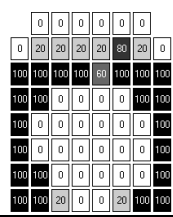 \\
\hline
\end{tabular}

Figure 15. EPG palatograms displaying percentage frequency of electrode activation over five repetitions during the production of the $/ \mathrm{r} / \mathrm{in} / \mathrm{rk} /$ sequences by speakers TP (top) and KN (bottom). 
productions compared to the more open articulations of the latter. In addition, more fronted production is evident for TP. Differences in the overall amount of contact in the alveolar and palatal zones between the speakers are also evident with generally more contact in the alveolar zone for TP and in the palatal zone for KN.

Finally, there were six tokens which were produced as trills with two constriction phases present and another six tokens which showed a possible second very open approximation gesture (Figure 16).

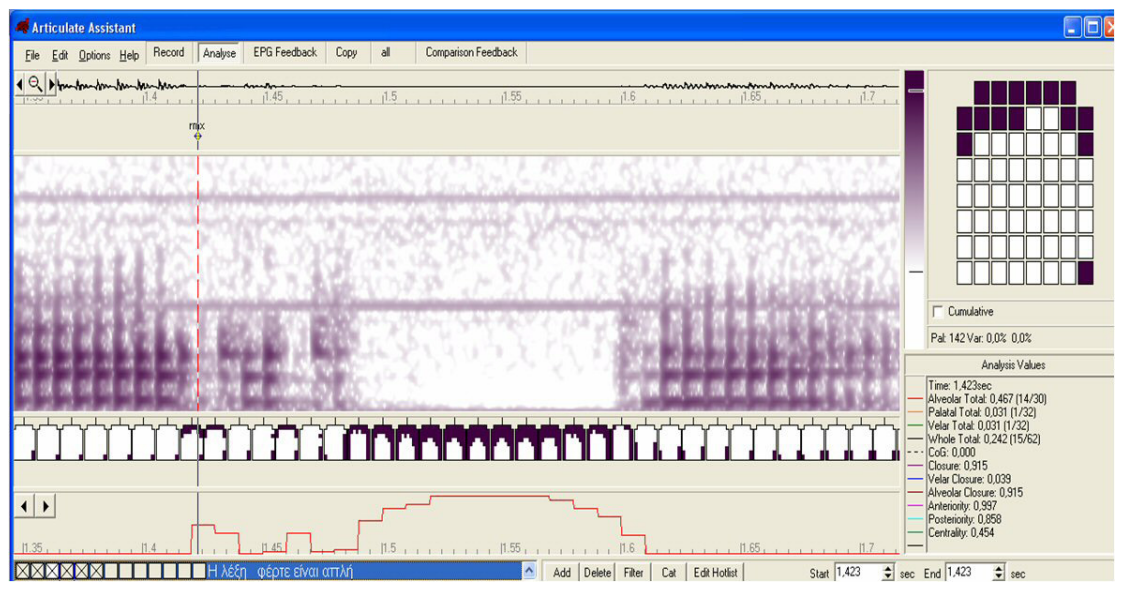

Figure 16. Acoustic and electropalatographic data for the rhotic in the word ['ferte] produced by speaker TP. Trill production of the rhotic is illustrated. The annotation line corresponds to the first frame of maximum contact/constriction in the alveolar zone during the first constriction phase. The corresponding palatogram is shown at the top right of the display. The palatograms below the spectrogram show presence of complete closure during both constriction phases.

\section{Discussion and Conclusion}

Both the acoustic and articulatory analysis showed that the rhotic is typically produced with a single constriction of short duration followed by a vocoid interval. The presence of the single constriction indicates the production of a tap and not a trill in $/ \mathrm{rC} /$ sequences. The duration of the constriction ranged between 22 and 28 ms, displaying considerably less variability than the constriction duration range of 11-50ms reported for $/ \mathrm{Cr} /$ clusters in Nicolaidis and Baltazani (2011), (cf. Nicolaidis 2001; Arvaniti 2007; Baltazani 2005, 2009). A very limited number of tokens (6 or possibly 12) out of the 749 analysed were produced as trills. 
As mentioned in the introduction, the presence of the vocoid during rhotic production in clusters and sequences has been documented in several languages (see section 1). Different interpretations have been offered for the presence of this vocoid. On the one hand, it has been interpreted to result from lack of temporal overlap between the articulatory gestures for the $/ \mathrm{r} /$ and the other consonant in the cluster or sequence (Riera \& Romero 2006; Romero 1996, 2008; Bradley 2004). On the other hand, Blecua (2001) argues that the vocoid is an inherent part of the rhotic itself based on the observation that the formant structure of the vocoid is similar to that of the tautosyllabic vowel.

While the presence of the vocoid has been documented in clusters and sequences, useful insights on the articulatory behaviour of the rhotic can be gained from the study of the rhotic in phrase initial or intervocalic position where its articulation is not affected by a preceding or following consonant. Data reported in Baltazani \& Nicolaidis (2012) show that the production of the rhotic in phrase initial position also involves a vocoid preceding the constriction phase. In addition, preliminary evidence of the presence of the vocoid when the rhotic is produced intervocalically is reported in the same study. Unpublished data on word final / $r$ / in Greek also document the presence of the vocoid following the constriction. These findings suggest that the rhotic is superimposed on a rhoticspecific vocalic gesture which is needed for the ballistic movement to occur. The vocoid is thus an inherent part of the rhotic itself (cf. Blecua 2001 for clusters and sequences).

This interpretation is corroborated by the results of the acoustic analysis. The formant structure of the vocoid was similar but more centralised than the nuclear vowel, suggesting that its quality depends on the nuclear vowel. Similar results have been reported in Nicolaidis \& Baltazani (2012) for $/ r /$ in phrase initial position. The similarity between the vocoid and the vowel on the other side of the tap constriction, especially for $/ \mathrm{Cr} /$ and $/ \mathrm{rC} /$ sequences, has been documented for other languages as well (e.g. Quillis 1993; Bradley 2001; Blecua 2001; Ramírez 2006; Savu 2012).

Further support for the tap interpretation is provided by the duration differences found between the vocoid and the constriction. Trills are typically produced with vocalic and consonantal intervals of equal durations (e.g. Recasens 1991), while our findings demonstrate that the vocoid is consistently longer than the constriction suggesting that the rhotic is not a trill.

The articulatory data provided evidence of variation in place and degree of constriction due to the context and the speaker. While the rhotic is always articulated in the alveolar zone (the four front rows of electrodes), its place varies due to the vocalic context and ranges between alveolar, retracted alveolar, advanced postalveolar and postalveolar. More advanced articulation is present in the front vowel contexts while more retracted production is overall evident in the back vowel environments. Some evidence of contextual influence on 
place of articulation from the following consonant was also present, although large variation was found. Rhotic production also varied in terms of the degree of constriction. Presence of complete constriction across one or more rows of electrodes was evident for some tokens while incomplete constriction was found for others. Tokens with incomplete constriction ranged from very constricted to very open articulations. The corresponding acoustic data included tokens with a stop-like pattern when complete constriction was present, tokens with presence of formants throughout the constriction when there was incomplete constriction indicating approximant production, and tokens with presence of noise during incomplete constriction. Similar findings have been reported for $/ \mathrm{Cr}$ / clusters and singleton $/ \mathrm{r}$ / in different prosodic positions in Greek (Nicolaidis and Baltazani 2011; Baltazani and Nicolaidis (2012)). In total, 57\% of the tokens were produced with incomplete constriction and more tokens with an open articulation were found in the context of a fricative compared to a stop. Important speaker variability in the total number of tokens produced with incomplete constriction was however found suggesting individual strategies in production. Inter- and intra-speaker variability was also found in the place of articulation of the rhotic, in the degree of constriction and in the total amount of contact in the alveolar and palatal zones.

Overall, the results on the contextual influence, in particular, evidence of V-to-r and C-to-r contextual effects, indicate that the tongue tip/blade coarticulates with neighbouring gestures during the production of the rhotic in $/ \mathrm{rC} /$ sequences similarly to findings reported for $/ \mathrm{Cr} /$ clusters and singleton /r/ in Greek (Nicolaidis and Baltazani 2011; Baltazani and Nicolaidis (2012)). Coarticulatory effects on the rhotic have also been reported for other languages (e.g. Recasens 1991; Recasens and Pallarès 1999).

In conclusion, the acoustic and articulatory data of this study and previous studies (Nicolaidis and Baltazani 2011; Baltazani and Nicolaidis (2012)) provide evidence that the Greek rhotic involves a single constriction produced by a rapid ballistic movement which is superimposed on a vocalic gesture. The presence of the vocoid in $/ \mathrm{rC}$ / sequences is part of this rhotic-specific vocalic gesture and is necessary for the ballistic movement to take place. 


\section{References}

Arvaniti, A. 2007. Greek phonetics: The state of the art. Journal of Greek Linguistics 8: 97-208.

Arvaniti, A. 1999. Standard Modern Greek. Journal of the International Phonetic Association 29: 167-172.

Baltazani, M. 2005. Phonetic variability of the Greek rhotic sound. Phonetics and Phonology in Iberia (PaPI) 05. Barcelona, Spain. Poster available at http://users. uoi.gr/mbaltaz/en/Papi05.

Baltazani, M. 2009. Acoustic characterization of the Greek rhotic in clusters. Selected Papers from the 18th ISTAL, Aristotle University, Thessaloniki, Greece, 87-95.

Baltazani, M. and K. Nicolaidis 2012. Production of the Greek rhotic in initial and intervocalic position: an acoustic and electropalatographic study. In Z. Gavriilidou, A. Efthymiou, E. Thomadaki \& P. Kambakis-Vougiouklis (eds) Selected Papers of the 10th International Conference on Greek Linguistics, Komotini,Greece: Democritus University of Thrace, 141-152.

Blecua Falgueras, B. 2001. Las vibrantes del español:manifestaciones acústicas procesos fonéticos. Ph.D. dissertation. Universidad Autónoma de Barcelona.

Bradley, T.G. 2001. The phonetics and phonology of rhotic duration contrast and neutralization. Ph.D. dissertation. Pennsylvania State University.

Bradley, T.G. 2004. Gestural timing and rhotic variation. In T.L. Face, (ed.), Laboratory Approaches to Spanish Phonology. Berlin: Mouton de Gruyter, 195220. 
Bradley, T.C. and B.S. Schmeiser. 2003. On the Phonetic Reality of Spanish /r/ in Complex Onsets. In P.M. Kempchinsky and C.-E. Piñeros (eds), Theory, Practice, and Acquisition: Papers from the 6th Hispanic Linguistics Symposium and the 5th Conference on the Acquisition of Spanish and Portuguese. Somerville, MA: Cascadilla Press, 1-20.

Colantoni, L. and J. Steele. 2005. Liquid asymmetries in French and Spanish. Toronto Working Papers in Linguistics 24: 1-14.

Gibbon, F. and K. Nicolaidis. 1999. Palatography. In W. Hardcastle and N. Hewlett (eds), Coarticulation. Cambridge: CUP, 229-245.

Harms, R.T. 1976. The segmentalization of Finnish 'nonrules'. Texas Linguistic Forum 5: 73-88.

Inouye, S. 1995. Trills, Taps and Stops in Contrast and Variation. Ph.D. Dissertation, University of Los Angeles, California.

Jannedy, S. 1994. Rate effects on German unstressed syllables. OSU Working Papers in Linguistics 44, 105-124.

Ladefoged, P. and I. Maddieson. 1996. The Sounds of the World's Languages. Cambridge: Blackwell.

Lindau, M. 1985. The story of /r/. In V.A. Fromkin (ed.), Phonetic Linguistics: Essays in Honor of Peter Ladefoged. Academic Press, 157-168.

Navarro Tomás, T. 1918. Diferencias de duración entre las consonantes españolas. Revista de Filología Española 5: 367-393.

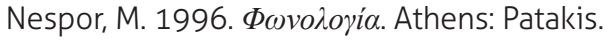

Nicolaidis, K. 2001. An electropalatographic study of Greek spontaneous speech. Journal of the International Phonetic Association 31: 67-85.

Nicolaidis, K. and M. Baltazani. 2011. An electropalatographic and acoustic study of the Greek rhotic in $/ \mathrm{Cr} /$ clusters. In Proceedings of the 17th International Congress of Phonetic Sciences, City University of Hong-Kong, 1474-1478.

Quilis, A. 1993. Tratado de fonología y fonética españolas. Madrid: Editorial Gredos.

Ramírez, C.J. 2006. Acoustic and Perceptual Characterization of the Epenthetic Vowel between the Clusters Formed by Consonant + Liquid in Spanish. In M. 
Díaz-Campos (ed.), Selected Proceedings of the 2nd Conference on Laboratory Approaches to Spanish Phonetics and Phonology. Somerville, MA: Cascadilla Proceedings Project, 48-61.

Recasens, D. 1991. On the production characteristics of apicoalveolar taps and trills. Journal of Phonetics 19: 267-280.

Recasens, D. and A. Espinosa. 2007. Phonetic typology and positional allophones for alveolar rhotics in Catalan. Phonetica 63: 1-28.

Recasens, D., E. Farnetani, ]. Fontdevila and M.D. Pallarès. 1993. An electropalatographic study of alveolar and palatal consonants in Catalan and Italian. Language and Speech 36: 213-234.

Recasens, D. and M.D. Pallarès. 1999. The study of $/ \mathrm{r} /$ and $/ \mathrm{r} /$ in the light of the 'DAC' coarticulation model. Journal of Phonetics 27: 143-169.

Riera, M. and J. Romero. 2006. $\mathrm{V}+/ \mathrm{l} /$ and $\mathrm{V}+/ \mathrm{r} /$ sequences in American English: a preliminary acoustic study. In Proceedings of the 29th AEDEAN International Conference, Jaén, Spain: Universidad de Jaén, Servicio de Publicaciones, 529-536.

Rochette, C.-E. 1973. Les groupes de consonnes en français:étude del'enchaînement articulatoire à l'aide de la radiocinématographie et de l'oscillographie. Quebec: Les presses de l'Université Laval.

Romero, J. 1996. Articulatory blending in lingual gestures. Journal of Phonetics 24: 99-111.

Romero, J. 2008. Gestural Timing in the Perception of Spanish $\mathrm{r}+\mathrm{C}$ Clusters. In L. Colantoni and J. Steele (eds), Selected Proceedings of the 3rd Conference on Laboratory Approaches to Spanish Phonology. Somerville, MA: Cascadilla Proceedings Project, 59-71.

Savu, C.F. 2012. An Acoustic Phonetic Perspective on the Phonological Behavior of the Rhotic Tap. Presentation in ConSOLE XX, University of Leipzig.

Vago, R. and M. Gósy. 2007. Schwa vocalization in the realization of /r/. Proceedings of the $16^{\text {th }}$ International Congress of Phonetic Sciences, Saarbrücken Germany, 505-509.

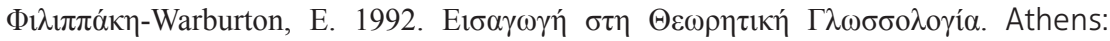
Nefeli. 


\section{Appendix}

The experimental material used for $/ \mathrm{rC} /$ sequences. The words in the table below were embedded in a carrier phrase.

\begin{tabular}{|c|c|c|c|c|c|}
\hline & $/ a /$ & le/ & $/ \mathrm{i} /$ & lo/ & $/ u /$ \\
\hline$/ \mathrm{p} /$ & 'arpa & erpe'to & 'tirpis & skorpo'xori & yur'punis \\
\hline$/ \mathrm{t} /$ & 'arta & 'ferte & 'sirtis & 'fortos & sur'tuko \\
\hline$/ \mathrm{k} /$ & 'marka & 'perces & 'circi & 'orkos & kur'kuti \\
\hline /f/ & kar'fara & aðer'fe & 'tirfi & 'korfos & fur'furi \\
\hline$/ \theta /$ & 'mar $\theta a$ & 'erӨete & 'sir $\theta$ ice & or' $\theta$ os & sur'$\theta$ un \\
\hline$/ x /$ & karxa'rias & 'erçete & 'irçisan & orxome'nos & xurxu'rizo \\
\hline
\end{tabular}

